УДК 316.3

DOI https://doi.org/10.32837/apfs.v0i27.929

\author{
А.В. Музылёв \\ ORCID ID: https://orcid.org/0000-0001-9943-6952 \\ магистр социологии, \\ аспирант кафедры политической социологии
}

Харьковского национального университета имени В. Н. Каразина

\title{
ОСОБЕННОСТИ КОНСТРУИРОВАНИЯ КОЛЛЕКТИВНОЙ ОБИДЫ ПОСРЕДСТВОМ КИНЕМАТОГРАФА (НА ПРИМЕРЕ СОВРЕМЕННЫХ УКРАИНСКИХ ФИЛЬМОВ)
}

Постановка проблемы. Социальные и политические перемены, которые происходят в обществе, часто находят отражение в разных сферах культуры и искусства. Таковыми могут быть музыка, литературы, живопись, кинематограф. В них находят отражение образы и представления о конкретных событиях и личностях. Их демонстрация в кино способствует укреплению и утверждению таких образов в реальной жизни.

Кинематограф для многих является не просто видом искусства или развлечением, но и источником получения информации касательно различных событий [1], поэтому художественные и документальные картины обладают большим конструктивистским потенциалом. Они могут демонстрировать и закреплять в коллективной памяти наиболее релевантные образы героев и жертв. Выход на экраны сразу нескольких картин, посвященных одной тематике, во-первых, демонстрирует ее значимость для общества, а во-вторых, позволяет сформировать у зрительской аудитории определенное мнение касательно представленных событий.

Сейчас в Украине сложились благоприятные условия для производства и проката фильмов, которые способствуют утверждению коллективной обиды, то есть такой модели поведения по отношении к агрессору, которая характеризуется явным негативным отношением к нему, отторжением. Коллективная обида возникает как одно из следствий «полученных» (то есть продемонстрированных на экране) травм. Это отношение к героям картины, которое затем можно переносить из мира кино в реальную жизнь. Кинематограф служит источником информации, которую усваивают зрители. Также они могут воспринимать модели поведения, продемонстрированные в фильме, как реальные. Демонстрируемые картины способны как создавать новых героев, так и укоренять в массовом сознании чувство обиды по отношении $\kappa$ агрессору, желание отомстить. Это способно привести к повышению уровня радикализма в обществе, что может проявляться в росте популярности крайне правых или крайне левых партий, погромах, повышении протестной активности.

Особенности фиксации различных событий и образов в коллективной памяти через кинема- тограф и визуальные методы изучают многие авторы, в частности Я. Ассман, Е. Волков, Е. Пономарева, Ю. Лотман, М. Ферро, Р. Росенстоун, К. Огнев, В. Миславский, Дж. Ритцер. Мы же рассматриваем кино в качестве одного из элементов, посредством которого можно сконструировать отношение к определенному событию или явлению.

Таким образом, целью статьи является рассмотрение специфики конструирования коллективной обиды в фильмах украинского производства. Исходя из поставленной цели, выдвигаем такие задачи:

1) выявить особенности отображения коллективной обиды в кинематографе;

2) проанализировать специфику отображения коллективной обиды в украинском кинематографе;

3) определить характерные приемы, которые используют в фильмах, направленных на установление коллективной обиды.

Изложение основного материала. Кинематограф является не просто развлечением, но и важным источником информации, особенно о событиях, в которых широкая аудитория разбирается не лучшим образом. В таких случаях даже художественный фильм может рассматриваться зрителями как документальная правда. Кинематограф - одна из тех сфер, благодаря которой проходит поддержание коллективной памяти [2]. Коллективная обида как часть коллективной памяти также может находить отражение в кино.

Если коллективная память в фильмах - это сам факт фиксации того или иного исторического события, то коллективная обида обычно проявляется не так очевидно. Она может проявляться в диалогах, характере взаимоотношений между персонажами. Классический пример - это ситуация, при которой положительный персонаж демонстрируется в качестве жертвы, а отрицательный - ее насильника, абьюзера. Таким образом, в отношении этого насильника или группы, к которой он принадлежит, конструируется коллективная обида. Однако это актуально в первую очередь для фильмов, в которых затрагиваются военные или политические события.

Главным образом коллективная обида конструируется посредством создания образов врага 
и жертвы. Первый предполагает демонстрацию особой жесткости по отношении к положительному герою картины. Она может проявляться в насилии, физической расправе, неуважении к символам той или иной группы, то есть конструируется отрицательный образ жестокого врага, который может использовать разные методы для достижения своих целей. Параллельно с этим отображение коллективной обиды - это еще и конструирование образа жертвы. Он включает целый комплекс факторов. Во-первых, полное отрицание собственной вины за произошедшую ситуацию (например, в военных фильмах отрицание вины за начало боевых действий). Во-вторых, демонстрация системы отношений, при которых положительный герой как раз и находится в образе жертвы. Также жертвенность предполагает угнетение героя, демонстрацию травм, с которыми ему пришлось столкнуться (как физических, так и моральных). Жертва - это тот, кто несправедливо столкнулся с ограничениями, дискриминацией, потерями.

Обычно картины содержат сразу два элемента. С одной стороны, создается образ врага, с другой стороны, создается образ жертвы. Чаще всего подобное можно встретить в фильмах, посвященных боевым действиям, например Второй мировой войне. Демонстрация жестокости со стороны нацистов, с одной стороны, и жертвы советских солдат или союзников, с другой стороны, - это классический пример конструирования коллективной обиды. Обычно она достаточно неявная, то есть демонстрируется просто жестокость (убийства, пытки, но демонстрируемые лишь эпизодически), что и позволяет конструировать по отношении к ним коллективную обиду. $K$ тому же такая система взаимоотношений обычно демонстрируется лишь фоново, а фильмы чаще повествуют личную историю.

Находит свое отражение коллективная обида и в фильмах, которые напрямую не посвящены потенциально травматическим событиям или историческим персоналиям. В них отражением обиды может быть буквально одна реплика или сцена. Такие картины являются не менее значимыми, поскольку в них коллективная обида хоть и выражается латентно, но оказывает на зрителей не меньшее воздействие.

Фильмы не становятся главным элементом конструирования коллективной обиды [3]. Обычно зрители знают о травмирующей ситуации и благодаря картине лишь пополняют свои знания. Также такие картины служат для того, чтобы сохранить в коллективной памяти информацию о том или ином событии. Например, регулярный выход фильмов, посвященных Второй мировой войне, способствует (в качестве одного из факторов) дальнейшему поддержанию интереса к событию.

Кино является важным инструментом конструирования реальности, поскольку на экране зрители часто могут видеть яркие и запоминающиеся образы [4]. Они хорошо усваиваются и в дальнейшем прочно ассоциируются с определенными событиями, явлениями, личностями. Причем в кино нередко используются гипертрофированные образы. Преувеличиваются достоинства одной стороны, а другая демонстрируется исключительно в негативном контексте. В этом и состоит элемент конструктивизма, поэтому картины чаще всего отражают авторский субъективный взгляд на события или же транслируют точку зрения, которая выгодна компаниям или корпорациям, которые финансируют проект.

Обычно кино рассчитано на достаточно широкую и разнообразную аудиторию. Это означает, что о событии, о котором идет речь в картине, смогут узнать не только эксперты в этой области, но и обыватели [5]. Также многие дети начинают смотреть фильмы гораздо раньше, чем читать специализированную литературу или проходить события на уроках истории в школе. Таким образом, они уже с детства запоминают различные образы и могут воспринимать одну сторону в качестве героев или просто относиться к ней положительно, а другую - в роли агрессоров.

Кино можно считать дополнительным элементом конструирования коллективной обиды, поскольку обычно оно лишь дополняет собой актуальные события. Так, хорошо известно, что еще в периоды войн снимались фильмы для поддержания боевого духа и сплочения солдат. Такие картины особенно интересны с точки зрения конструирования коллективной обиды. Фактически в них зрители видят актуальные события, продемонстрированные на экране. В героях картины также многие могут узнать себя или своих знакомых, что помогает разделить сопереживание главным персонажам, поэтому еще во время Второй мировой войны каждая из сторон выпускала в большом количестве пропагандистские картины.

Достаточно часто можно столкнуться с тем, что фильм выполняет сразу две функции. С одной стороны, он содействует героизации образа солдат, а с другой стороны, он конструирует обиду по отношении к агрессору, его войску и политическому руководству. Также достаточно популярным приемом является демонстрация гибели положительного героя, который теряет жизнь в результате действий врагов. Это помогает сформировать по отношению к ним негативное отношение. Такой прием является особенно эффективным в условиях наличия реальных боевых действий. В таких случаях зрителям несложно сопоставить себя с героями и образами, продемонстрированными на экране. Все дело в том, что одна из главных задач кинематографа - это производство эмоций. При просмотре фильма зритель будет сопереживать главному герою картины и «впитывать» всю информацию 
о событии. Он может узнать как реальные факты, так и вымышленные, поэтому коллективная обида может основываться на легендах, мифах. На экране можно воплотить разные события, и вовсе не обязательно, чтобы они были достоверными. Важно вызвать у зрителя эмоции, что позволит зафиксировать продемонстрированные образы.

Хотя большинство фильмов, посвященных военной тематике, конструируют коллективную обиду, такая модель поведения не становится актуальной для зрителей. Наиболее распространенная причина - нерелевантность продемонстрированных событий. Это можно сказать о большинстве картин, посвященных Второй мировой войне. Во-первых, в них обычно конструируется коллективная обида именно к нацистскому режиму, а не к Германии, а во-вторых, сейчас между странами нормальные политические отношения и нет очевидных конфликтов, поэтому такие картины служат скорее не для актуализации коллективной обиды, а для фиксации событий в коллективной памяти. Фильмы же, как и книги или различные исторические факты, могут использоваться в качестве дополнительных элементов конструирования коллективной обиды при условии наличия актуальных противостояний, то есть кинематограф выступает еще одной сферой, в которой можно уже в новом формате (не в качестве новостного сюжета или статьи) увидеть своего обидчика.

Конструирование коллективной обиды - это распространенный прием, одной из целей которого является сплочение вокруг общей травмы, беды. Общее чувство призвано объединить представителей разных групп вокруг одних ценностей. Во время войн или других конфликтных ситуаций такие картины выступают в качестве дополнительной мотивации и даже радикализации, а в последующем способствуют сохранению в коллективной памяти информации о значимых событиях.

В связи с этим производство и демонстрация таких фильмов являются особенно актуальными для Украины. Когда страна оказалась в условиях боевого конфликта, а также политического кризиса, достаточно быстро началось конструирование коллективной обиды посредством СМИ. Утверждению коллективной обиды содействовали актуальные новости, и долгое время военный конфликт на Востоке Украины никак не был отражен в кинематографе, что достаточно удивительно, ведь о событиях периода Революции Достоинства фильмы выходили уже в 2014 году, правда речь идет о документальных картинах («Майдан», «Все пылает»).

Тематика АТО начинает демонстрироваться в художественных фильмах только с конца 2017 года, то есть спустя 3,5 года с начала боевых действий. Можно сказать, что реакция украинского кинематографа на актуальные политиче- ские события оказалась достаточно медленной. Впрочем, поскольку боевые действия продолжаются, то фильмы, выходящие в прокат, помогают конструировать коллективную обиду и служат отражением текущих событий.

В своем исследовании мы обращаем внимание на фильмы украинского производства, поскольку события, связанные с АТО, актуальны в первую очередь для нашей страны. Если же брать широкий украинский прокат, то в нем преобладают другие коллективные обиды. В первую очередь это тематика Второй мировой войны.

Итак, первым фильмом, посвященным актуальным политическим событиям, стала картина «Киборги» (2017 год, реж. А. Сейтаблаев). Всего же за период 2017-2019 годов вышли сразу несколько фильмов, связанных с тематикой АТО, а именно «Позывной «Бандерас»» (2018 год, реж. 3. Буадзе), «Иловайск 2014. Батальон «Донбасс»» (2019 год, реж. И. Тимченко), «Донбасс» (2018 год, реж. С. Лозница). Это фильмы, посвященные актуальным политическим событиям. Конструирование коллективной обиды в них в первую очередь проявляется в демонстрации образов врага и жертвы, демонстрации ненависти к определенной нации или ее представителям.

Также обращает на себя внимание тот факт, что в этот период в широкий украинский прокат вышел еще ряд картин, которые конструируют коллективную обиду схожим образом. Это «Тайный дневник Симона Петлюры» (2018 год, реж. О. Янчук), «Червонный» (2017 год, реж. З. Буадзе), «Круты 1918» (2018 год, реж. А. Шапарев). Используемые в них приемы конструирования коллективной обиды являются достаточно распространенными. Это создание, с одной стороны, образа врага, а с другой стороны, образа жертвы. Причем апелляция к событиям из исторического прошлого - это попытка продемонстрировать, что конфликтные отношения народов случались на разных исторических этапах. Поскольку эти картины были проанализированы нами ранее [6], то в этой работе предлагаем остановиться на еще более актуальных примерах конструирования коллективной обиды.

Даже в 2020 году, несмотря на серьезные ограничения в прокате, вышло сразу несколько картин, способствующих конструированию коллективной обиды. Это фильмы «Черкассы» (2019 год, реж. Т. Ященко), «Наши котики» (2020 год, реж. В. Тихий), «Східняк»(2019 год, реж. Э. Ива). Также за последний год в широкий прокат вышло сразу 2 документальных фильма, посвященных теме АТО. Это картины «Осколки» (2020 год, реж. А. Якубов) и «Земля голубая, будто апельсин» (2020 год, реж. И. Цилик). Это первые документальные фильмы, посвященные именно событиям, связанным с АТО, которые были выпущены в широкий прокат. Сразу отметим, что хоть их 
относительно немного, если брать общее количество картин, вышедших в прокат, но поскольку тема актуальная и используется в украинском кинематографе уже не первый год, то за счет регулярного выпуска таких картин удается сконструировать определенное отношение к происходящим событиям.

Фильмы, вышедшие в прокат в 2020 году, посвящены теме ATO, а также судьбе последнего украинского корабля в Крыму. Одна из ключевых их функций - поддержание морально-боевого духа солдат, а также закрепление в общественном сознании образа героев. Конструированию коллективной обиды они часто содействуют за счет небольших эпизодов, которые демонстрируются в фильмах.

Начнем с картины «Черкассы», которая повествует о судьбе последнего украинского корабля в Крыму. Лишь один такой поступок создает образ героя, и именно героизация украинских моряков является центральным элементом этой картины. Причем, что характерно, в ней сложно выделить очевидного главного персонажа (который изначально есть, но со временем его экранного времени становится все меньше), что позволяет транслировать такой образ не на одного конкретного моряка, а на всю команду, которая сохранила верность украинскому народу.

Конструирование коллективной обиды в фильме можно проследить в нескольких фрагментах. Во-первых, один из персонажей говорит, что их «не готовили воевать с братским народом». Так проходит утверждение образа жертвы, которыми оказались моряки. Так демонстрируется не столько неготовность военных к боевым действиям, сколько попытка показать, насколько подлый поступок был совершен.

Дальнейший ход событий в картине только содействует утверждению коллективной обиды. Так, в одном небольшом эпизоде герои картины рассказывают о пропаже крымско-татарского активиста, то есть создается еще один образ невинной жертвы, а также происходит утверждение тезиса о репрессиях в отношении политических оппонентов. Еще одним эпизодом, важным с точки зрения коллективной обиды, является фрагмент с нападением российских военных на корабль, когда группа вооруженных лиц оказывается на судне. Таким образом, транслируется образ врага, агрессора, который совершает незаконное проникновение и силой заставляет подчиниться. Чуть позже российские военные уже убивают одного из моряков, что создает образ сакральной жертвы. В совокупности с историей изгнания украинских моряков из их родного места дислокации эпизоды, о которых шла речь выше, содействуют воспроизводству травмирующего опыта. Он заключается в насильственном изгнании, убийстве украинского моряка, военном вторжении.
Несмотря на то, что многие из указанных эпизодов не занимают центральное место в картине, ее общая концепция и демонстрация таких ролевых отношений могут считаться элементами конструирования коллективной обиды. Однако более отчетливо в фильме все же прослеживается создание образа героев в отношении украинских военных, которые отказались сдаться.

В совершенно ином ключе рассказывает о событиях в зоне ATO картина «Наши котики». В ней авторы в первую очередь высмеивают идеологического и военного противника, воспроизводя в гротескной форме ряд стереотипов. Несмотря на юмористический характер картины, в ней есть несколько важных эпизодов с точки зрения конструирования коллективной обиды. Так, это создание образа врага, которого олицетворяют военные, чеченцы (как отдельная национальная группа и наемники, пришедшие на чужую землю), политическое руководство, которое «боготворят» боевые противники, а также местное население Донбасса, которое враждебно относится к украинским солдатам. Характерным является эпизод на 35 минуте фильма, когда один из украинских военных говорит в отношении жителей Донбасса, которые не поддерживают воинов АТО, яркую фразу «Я людей там не вижу». Так происходит конструирование образа врага в отношении не столько внешнего оппонента, сколько внутреннего. Это достаточно распространенный прием, который ранее можно было увидеть в таких картинах, как «Позывной «Бандерас»», «Иловайск 2014. Батальон "Донбасс»», «Донбасс». Этот прием позволяет утвердить образ внутреннего врага. Причем, что характерно и для фильма «Наши котики», в картинах демонстрируется достаточно стереотипный образ, который включает ненависть ко всему украинскому (особенно языку), непоколебимую веру российским СМИ. В этой картине демонстрации карикатурных образов уделено особое внимание, ведь фактически именно на этом она и строится.

Однако помимо шуток в фильме есть эпизоды, в которых воспроизводится травмирующий опыт, например, в сценах, где говорится, что враг сейчас собирается устроить зачистку территории. Так, в очередной раз в картине создается образ враждебной стороны, агрессора, который нацелен на физическое устранение украинцев. События АТО воспроизводятся и закрепляются в общественном сознании, пусть и в несколько необычной форме, которая предполагает высмеивание прямого оппонента, а также собственных недочетов.

Еще один фильм, который конструирует коллективную обиду, - это «Східняк». Картина основана на реальных событиях, и в ней рассказывается о боевых буднях украинских военных, одним из которых является местный житель, а другим житель западной части страны. Для этого фильма 
характерна более традиционная демонстрация ролей, в качестве героев показаны украинские солдаты, также происходят демонстрация боевых действий, воспроизведение травмирующего опыта. Идет рассказ о конкретных боевых потерях, которые были получены на фронте («у нас один 300-й»). При помощи таких простых приемов проходит утверждение базисных тезисов о жертвах с украинской стороны. Картина «Східняк» больше остальных направлена именно на создание положительного образа украинских военных, а не на конструирование образа врага, поэтому несколько отличается от фильмов, схожих по тематике. Она скорее призвана продемонстрировать, что на Донбассе есть немало людей, которые придерживаются проукраинской позиции.

Аналогичные образы можно встретить в картинах, которые выходили в прокат ранее, в 20182019 годах, поэтому можно сказать, что для украинского кинематографа характерна демонстрация "раскола», который произошел между жителями Донбасса, одна часть которых перешла на сторону сепаратистов, а другая вступила в ряды ВСУ. Так, происходит утверждение в коллективном сознании образа проукраинских и сепаратистских жителей региона, причем образ последних часто опирается на их максимально стереотипное восприятие, что особенно характерно для первых фильмов, посвященных тематике АТО.

Каждую из представленных и проанализированных картин можем рассматривать в качестве элементов конструирования коллективной обиды, опираясь на актуальную политическую повестку дня, то есть они дополняют новостные сюжеты, конструируют героический и жертвенный образ украинских военных. Они часто оказываются жертвами военных оппонентов, что способствует формированию к ним негативного отношения, желания отомстить.

Современные украинские фильмы выполняют распространенную функцию, а именно они помогают зрителям увидеть на экране популярные и актуальные образы, которые до этого демонстрировались только в новостных сюжетах. Так, проходит их утверждение и конструирование. Помимо прочих элементов, заметную роль играет демонстрация травмирующего опыта, с которыми столкнулись украинские военные и местные жители. Это содействует утверждению модели поведения, которая характеризуется крайне негативным отношением к агрессору (который практически в каждой картине заявлен четко), а также жалости к собственным невинным жертвам, то есть происходит конструирование коллективной обиды.

Выводы. Коллективная обида в кинематографе чаще всего проявляется в создании образов жертвы и врага в отношении демонстрируемых персонажей. Поскольку коллективная обида - это мо- дель поведения, которая создается искусственно, именно выбор тематики картины, демонстрируемые в ней роли и взаимоотношения персонажей приводят к ее появлению и утверждению.

В украинском кинематографе травмы и обиды начали широко отображаться после 2017 года, то есть авторам картин потребовалось несколько лет для создания фильмов (после начала проведения боевых действий как естественного катализатора коллективной обиды), в которых будут отражены популярные образы и герои. В первую очередь современные картины посвящены тематике проведения ATO. В первых фильмах, которые вышли в прокат в 2017-2019 годах, были утверждены образы жертвы и агрессора, которые нашли свое продолжение в картинах, выпущенных уже в 2020 году. Однако сейчас увеличилось тематическое разнообразие фильмов. Теперь это не только военно-патриотические драмы, но и комедии, которые в юмористическом ключе демонстрируют образы украинских военных, вражеских сил, а также содействуют утверждению и распространению коллективной обиды. Происходит это за счет небольших эпизодов, в которых отражаются образы врага и жертвы, неуважение к национальным символам, оскорбления.

Несмотря на относительную немногочисленность проанализированных картин, они вырабатывают единую модель отношения к украинским военным и вражеским войскам. Поскольку конфликт остается актуальным, то это делает дальнейшее производство фильмов, которые конструируют коллективную обиду, более чем вероятным. Они помогут не только поддерживать боевой дух, но и консолидировать общество касательно вопросов национальной безопасности и единства.

\section{Jumepamypa}

1. Волков Е., Пономарева Е. Игровое кино как исторический источник для изучения культурной памяти. Вестник ЮУрГУ. Серия «Социально-гуланитарные науки». 2012. Вып. 18. № 10. С. 22-25.

2. Ассман Я. Культурная память: письмо, память о прошлом и политическая идентичность в высоких культурах древности / пер. с нем. М. Сокольской. Москва : Языки славянской культуры (ЯСК), 2004. 368 с.

3. Лотман Ю. Память в культурологическом освещении. Избранные статьи : в 3 т. Т. 1. Таллинн : Александра, 1992. С. 200-202.

4. Ферро М. Кино и история. Вопросы истории. 1993. № 2. C. $47-57$.

5. Ерохина Т. Феномен памяти в массовой культуре: контрпамять и постпамять в отечественном кинематографе. Ярославский педагогический вестник. 2017. № 5. С. 269-274.

6. Музылёв А. Конструирование коллективной обиды посредством кинематографа: украинский контекст. Science and Education a New Dimension. Humanities and Social Science. Budapest. 2020. № VIII (41). C. 81-84. 


\section{Анотація}

Музильов О. В. Особливості конструювання колективної образи за допомогою кінематографа (на прикладі сучасних українських фільмів). - Стаття.

У статті розглянуто особливості конструювання колективної образи за допомогою кінематографа. Розглянуто теоретичні основи роботи, а саме статті дослідників, які вивчають правила конструювання та утвердження колективної пам'яті в кінематографі. Колективна образа розглядається саме як частина пам'яті, в якій вона закріплюється за допомогою такого способу, як перегляд фільмів.

Виявлено основні особливості відображення колективної образи в кіно. Найчастіше для її конструювання використовуються образи ворога і жертви. Вони гіпертрофовані, жертва постає виключно в позитивному світлі, практично без недоліків. Образ ворога створюється як образ жорстокого, брутального, зневажливого, який готовий фізично і морально принизити жертву. Позитивний персонаж стає жертвою дискримінації, військової агресії, інших проявів неповаги.

Зображення образів жертви і ворога в картинах сприяє конструюванню ставлення до різних соціальних груп в суспільстві. Люди сприймають моделі поведінки, продемонстровані на екрані, як релевантні, а потім відтворюють їх у реальному житті.

Проведене дослідження демонструє, що в Україні на тлі актуалізації військових і політичних проблем регулярно випускаються в широкий прокат фільми, які конструюють колективну образу. Серед картин, що вийшли в прокат у 2020 році, до таких можна віднести «Східняк», "Черкаси», «Наші котики». У них конструюється образ українських військових не тільки як героїв і захисників Батьківщини, але й як безневинних постраждалих, які стають жертвами обставин. Для картин характерні героїзація воїнів і демонстрація жертв, з якими зіткнулися військові. Несправедливість щодо них приводить до формування колективної образи як відповіді на ті бойові втрати, з якими довелося зіткнутися.

Також у фільмах українського виробництва регулярно відтворюється образ ворога, який демонструється як жорстокий, підступний, що порушує наявні міжнародні домовленості. Його втілює як воєнне, так і політичне керівництво.

Демонстрація таких картин сприяє консолідації певної частини населення навколо єдиних цінностей, а також посиленню негативного сприйняття ворога.

Ключові слова: колективна образа, колективна пам'ять, травма, кінематограф, образ жертви, образ ворога.

\section{Summary}

Muzylov O. V. Peculiarities of constructing a collective resentment through a cinematographer (on the example of modern Ukrainian films). - Article.

The article deals with the peculiarities of constructing a collective resentment with the help of cinema. Theoretical bases of work are considered - its articles of researchers who consider rules of designing and the statement of collective memory in a cinema. The collective resentment is considered as a part of memory in which it is fixed by means and such way as viewing of films.

The main features of the reflection of the collective resentment in cinema are revealed. Images of the enemy and the victim are most often used for its construction. They are hypertrophied; the victim appears only in a positive light, almost without flaws. The image of the enemy is created as cruel, brutal, contemptuous, who is ready to physically and morally humiliate the victim. A positive character becomes a victim of discrimination, military aggression and other manifestations of disrespect.

The depiction of the images of the victim and the enemy in the paintings helps to construct attitudes towards different social groups in society. People perceive the patterns of behavior shown on the screen as relevant and then reproduce them in real life.

The study shows that in Ukraine, against the background of the actualization of military and political problems, films that construct a collective resentment are regularly released. Among the paintings released in 2020 include: "Skhidnyak", "Cherkasy", "Our Cats". They construct the image of the Ukrainian military not only as heroes and defenders of the homeland, but also as innocent victims who become victims of circumstances. The paintings are characterized by the heroization of soldiers and the demonstration of victims faced by the military. Injustice towards them leads to the formation of collective resentment in response to the combat losses we had to face.

Also in Ukrainian films, the image of the enemy is regularly reproduced, which is shown as cruel, insidious, which violates existing international agreements. It is embodied in both military and political leadership.

Demonstration of such pictures helps to consolidate a certain part of the population around common values, as well as to strengthen the negative perception of the enemy.

Key words: collective resentment, collective memory, trauma, cinema, image of the victim, image of the enemy. 